\title{
BMJ Open What does it take to provide clinical interventions with temporal consistency? A qualitative study of London hyperacute stroke units
}

\author{
Georgia B Black (D) , ${ }^{1}$ Angus I G Ramsay, ${ }^{1}$ Abigail Baim-Lance,${ }^{2}$ Jeannie Eng, ${ }^{3}$ \\ Mariya Melnychuk, ${ }^{4}$ Penny Xanthopoulou (D) , ${ }^{5}$ Martin M Brown, ${ }^{6}$ Stephen Morris, ${ }^{1}$ \\ Anthony G Rudd, ${ }^{7}$ Robert Simister, ${ }^{8}$ Naomi J Fulop (iD ${ }^{1}$
}

To cite: Black GB, Ramsay AIG, Baim-Lance A, et al. What does it take to provide clinical interventions with temporal consistency? A qualitative study of London hyperacute stroke units. BMJ Open 2019;9:e025367. doi:10.1136/ bmjopen-2018-025367

- Prepublication history and additional material for this paper are available online. To view these files, please visit the journal online (http://dx.doi org/10.1136/bmjopen-2018025367).

GBB and AIGR are joint first authors.

Received 12 July 2018 Revised 15 May 2019 Accepted 13 June 2019

\section{Linked}

http://dx.doi.org/10.1136/ bmjopen-2018-025366

Check for updates

(C) Author(s) (or their employer(s)) 2019. Re-use permitted under CC BY. Published by BMJ.

For numbered affiliations see end of article.

Correspondence to Dr Georgia B Black; g.black@ucl.ac.uk

\section{ABSTRACT}

Objectives Seven-day working in hospitals is a current priority of international health research and policy. Previous research has shown variability in delivering evidencebased clinical interventions across different times of day and week. We aimed to identify factors influencing such variations in London hyperacute stroke units (HASUs).

Design Interview and observation study to explain patterns of variation in delivery and outcomes of care described in a quantitative partner paper (Melnychuk et a). Setting Eight HASUs in London.

Participants We interviewed HASU staff ( $n=76)$, including doctors, nurses, therapists and administrators. We also conducted non-participant observations of delivery of care at different times of the day and week ( $n=45 ; \sim 102$ hours). We analysed the data for thematic content relating to the ability of staff to provide evidence-based interventions consistently at different times of the day and week. Results Staff were able to deliver 'front door' interventions consistently by taking on additional responsibilities out of hours (eg, deciding eligibility for thrombolysis); creating continuities between day and night (through, eg, governance processes and staggering rotas); building trusting relationships with, eg, Radiology and Emergency Departments and staff prioritisation of 'front door' interventions. Variations by time of day resulted from reduced staffing in HASUs and elsewhere in hospitals in the evenings and at the weekend. Variations by day of week (eg, weekend effect) resulted from lack of therapy input and difficulties repatriating patients at weekends, and associated increases in pressure on Fridays and Mondays.

Conclusions Evidence-based service standards can facilitate 7-day working in acute stroke services. Standards should ensure that the capacity and capabilities required for 'front door' interventions are available 24/7, while other services, for example, therapies are available every day of the week. The impact of standards is influenced by interdependencies between HASUs, other hospital services and social services.

\section{INTRODUCTION}

Seven-day provision of consistent, highquality urgent and emergency care settings
Strengths and limitations of this study

- This is the first study to observe 7-day working practices to understand how temporal variation and consistency in clinical interventions is created.

- We interviewed a wide range of clinical professions to build a diverse picture of hospital practices; a limitation is that we did not interview all relevant professionals, especially outside the hyperacute stroke unit (HASU).

- We observed HASUs and other areas of the hospital at different times of day and night to see what is done differently.

- Our paper is partnered with a statistical analysis of temporal variations in patient admission, delivery of evidence-based interventions and outcomes, creating a full mixed methods approach.

- This study was focused on London's HASUs: lessons may not apply to all hospital contexts.

is an international research and policy priority. ${ }^{1-6}$ This is motivated by 15 years of attention placed on the enigmatic "weekend effect' and other temporal variations, ${ }^{7}$ scrutinising mortality and other outcomes for those admitted at the weekend compared with during the week. ${ }^{5-14}$ Varying features that may explain differential outcomes include staffing levels ${ }^{8}$ and patient mix, ${ }^{15}$ leading to widespread interest in studying weekend organisational features. $^{716}$

For urgent stroke care, recent studies have shown that temporal variation in mortality is now decreasing ${ }^{17}{ }^{18}$ including in London's centralised 'hub and spoke' model ${ }^{19}$ and in the USA 'comprehensive stroke centres'. London has eight 'hub' units which are designated as hyperacute stroke units (HASUs). These units were opened in 2010 following a reorganisation of the London stroke model to create a small number of 24-hour acute assessment and treatment centres (the 'hub') 
linked to a network of stroke units across the city (the 'spokes') capable of receiving patients from the HASU for ongoing stroke care. This reorganisation of care has attracted interest through significant improvements in evidence-based care $^{20}$ and greater reductions in mortality ${ }^{21}$ compared with the rest of England. All eight HASUs are subject to the same service specifications with respect to staffing levels of key groups, access to imaging and access to dedicated stroke beds and all are required to provide a 24-hour service capable of rapid assessment by a stroke team, early treatment using thrombolysis (clotbusting drugs) if needed, high-dependency monitoring and a 24 -hour specialist team. ${ }^{22}{ }^{23}$ At the time of our study, no HASU was providing a formal thrombectomy service for stroke associated with large vessel occlusion, but currently three of the eight HASUs provide 7-day thrombectomy services and one of these is a 24-hour service. Further reorganisation of the London model is currently in progress with the designation of a subset of HASUs that can can provide centralised thrombectomy. The model is governed by the London Stroke Strategy which imposes tariff-linked requirements for staff level consistency and sufficient evidence-based care at all times; this strategy may have facilitated better outcomes. ${ }^{22}$ We show in a companion paper ${ }^{24}$ that in the London HASUs, there was:

1. No variation by day/time of admission in 3-day mortality or disability at hospital discharge.

2. No variation by day/time of admission in delivery of 'front door' interventions, such as stroke nursing assessment, brain scanning and thrombolysis measures.

3. Significant variations by day/time of admission in other interventions (including timely consultations and assessments with stroke specialists and therapies, and length of hospital stay).

In this paper, we set out to explore how acute care interventions are delivered with temporal consistency in centralised acute stroke services, and why some care interventions are resistant to temporal consistency by examining the organisation of services at different times of day/week.

\section{METHODS}

Our methods are reported according to Consolidated criteria for Reporting Qualitative Research reporting guidelines. $^{25}$

\section{Recruitment and sample}

Authors GBB, JE, PX and AB-L conducted 76 interviews with HASU staff and 45 non-participant observations of HASU activity over the day, night, week day and weekend (including HASU team meetings and care provision across the acute stroke pathway) over approximately 102 hours. GBB, PX and AB-L have doctoral degrees, extensive interview training and research experience. JE was trained in interviewing for this study and has a background in stroke occupational therapy. Thus, the team had 'insider' knowledge used to interpret behaviours and build rapport, but also 'naive' outsider perspective used to ask taken-for-granted questions of the staff. JE conducted informal discussions with ward managers from each site to establish staff numbers and seniority on the ward, the composition of staff attending suspected stroke calls in the emergency department (ED) and the availability of scans across the week.

\section{Non-participant observations}

We conducted non-participant observations at least four times at each HASU site: two visits in the weekday, one in the evening during the week and one at the weekend, with additional visits to confirm or add to our findings. We collected data on various aspects of HASU activity likely to influence care provision, guided by clinical interventions in our quantitative analysis, and our initial observations (see table 1 ).

We initially structured observations so that availability of staff and key processes (eg, handover and ward rounds) were covered. Subsequently we targeted our observations toward our emerging analysis, such as following patients' journeys from the ED to the HASU ward, and shadowing the nurse-in-charge and consultants to understand their roles.

We gained global written consent for observations from service leads and from a selection of staff at team meetings. Thereafter, verbal consent was given by staff members for researchers to make observations of staff meetings and of care provision.

\section{Interviews}

Staff were sampled purposively to ensure coverage of a range of professional roles within all eight HASUs, with perspectives on the clinical interventions analysed in our accompanying paper in this issue ${ }^{24}$ (eg, interpreting brain scans, thrombolysis, therapy assessments) including medical, nursing, therapy and administrative or managerial staff (table 2).

Researchers approached staff during the observation work and through existing contacts with study

Table 1 Summary of activities observed during nonparticipant observations

\begin{tabular}{ll}
\hline Activities observed & Total (of eight sites) \\
\hline 'Front door' activity & $7 / 8$ \\
\hline Ward round & $6 / 8$ \\
\hline Multidisciplinary team & $7 / 8$ \\
\hline 16:00 catch up meeting & $3 / 4^{\star}$ \\
\hline Nurse handover & $8 / 8$ \\
\hline Bed meeting & $6 / 8$ \\
\hline Discharge & $4 / 8$ \\
\hline Total conducted & 41 \\
\hline
\end{tabular}

Purposive sampling of observations is described under Methods section.

*Only four hyperacute stroke units have this activity. 
Table 2 Summary of interviewees

\begin{tabular}{lc}
\hline Profession & n \\
\hline Consultant physician* & 11 \\
\hline Junior doctor† & 15 \\
Senior nurse & 7 \\
Stroke nurse & 8 \\
\hline Research nurse & 1 \\
Physiotherapist & 10 \\
\hline Occupational therapist & 8 \\
Speech and language therapist & 8 \\
\hline Stroke coordinator§ & 8 \\
\hline Total conducted & 76 \\
\hline
\end{tabular}

*Includes lead consultants.

†ncludes specialist registrars and senior house officers. ‡lncludes matrons and ward managers.

§Includes stroke coordinators, facilitators and administrative staff.

information, stating that participation would be confidential and anonymously presented in publications. Interviews were conducted with fully informed, written consent and in private settings, according to a semistructured topic guide (online supplementary file A) with the aim of understanding temporal variations from the staff perspective, including typical daily activities and attitudes toward working in and out of hours. Interviews lasted between $20 \mathrm{~min}$ and an hour. No field notes were taken, but each interview was discussed with the other team members. Interviews were audio recorded and transcribed verbatim.

\section{Analysis}

Quality and trustworthiness were maintained through a select number of joint observations and interviews to sensitise ourselves to pertinent contextual issues, and regular reflexive discussions between the researchers. We analysed data in three phases, following the methodological principles of inductive/deductive thematic analysis. ${ }^{26}$ First, four researchers (GBB, AB-L, JE, AGR) developed codes through an analysis of 20 interview transcripts, using independent and joint coding to develop interrater consistency, and these codes were then discussed with the wider research team. Second, we performed further deductive coding of the remaining data using a broad coding framework developed in response to the research questions. We used Microsoft Word and Excel to manage the data. The third phase developed iteratively by group interpretation of the coded data, focusing on the research questions and unexpected findings. Finally, we mapped the results against the variations in practice across the 7-day week found in our analysis of the performance data for care provision in London HASUs set out in Melnychuk et $a l^{24}$ in particular the distinction between 'front door' clinical interventions (which were provided consistently) and other interventions (which were not).

\section{Patient and public involvement}

Two stroke patient representatives contributed to our study protocol, research questions and discussions of interim findings presented at steering committee meetings in June 2015 and July 2016. They raised issues related to staff handover and confirmed the importance of the interface between hospital and social services, which we incorporated into our analysis.

\section{RESULTS}

London HASUs deliver 'front door' clinical interventions, including brain scans, thrombolysis and swallow assessment without significant temporal variation. ${ }^{24}$ Length of stay showed significant variation without a clear temporal trend, assessment by a stroke physician within 12 or 24 hours varied by time of day and assessments by therapists varied by the day of the week. Care quality was worse for patients admitted on a Friday.

In the following sections, we present: (1) factors that may explain why 'front door' interventions showed temporal consistency, as well as some unintended consequences of the strategies London HASUs employed and (2) factors that may explain why other interventions and outcomes show significant temporal variations (table 3 ).

\section{Factors influencing temporally consistent care}

The London HASU standards required that HASUs have 24/7 availability of staff who are trained to assess eligibility for and deliver thrombolysis; this was normally completed by a team of medical and nursing staff who are on stand-by to immediately attend patients at ED when alerted to new potential patients with thrombolysis by the ED team (see figure 1).

Thrombolysis was administered by the stroke team where appropriate, after a battery of clinical and imaging tests had been conducted. The time taken to complete this process is one of the core performance metrics by which each treating unit is measured. Each HASU attempted to make this pathway as efficient as possible having a designated 'thrombolysis team' irrespective of clinical activity elsewhere in the stroke service and through local arrangements with radiology to guarantee that $100 \%$ of patients with stroke potentially eligible for thrombolysis are scanned within the next CT scan slot. However, as detailed in figure 2, the staff supporting 'front door' activity reduced both in number and seniority in the evenings and on weekends. As a result, the HASU teams made significant adaptations out of hours, including extending roles and responsibilities, and introducing processes to ensure continuity between different times of day.

\section{Adapting and extending roles}

At all times of day, stroke specialist registrars and senior house officers (junior doctors) made decisions about thrombolysis with consultant telephone support. However, observations and interviews suggested that in 
Table 3 Themes as they relate to consistently and inconsistently provided clinical interventions

\begin{tabular}{|c|c|c|}
\hline & Theme & Impact \\
\hline \multirow{3}{*}{$\begin{array}{l}\text { Factors influencing temporally } \\
\text { consistent care in nursing } \\
\text { assessments, CT scans and } \\
\text { thrombolysis }\end{array}$} & Adapting and extending roles & $\begin{array}{l}\text { At night the consultant was only called for positive } \\
\text { confirmation if the registrar thought a patient eligible } \\
\text { for thrombolysis. }\end{array}$ \\
\hline & $\begin{array}{l}\text { Creating continuities between } \\
\text { different times of day }\end{array}$ & $\begin{array}{l}\text { HASU staff created continuities between team } \\
\text { members operating at different times of day/week. } \\
\text { Handover meetings, multidisciplinary team meetings } \\
\text { and ward rounds. }\end{array}$ \\
\hline & $\begin{array}{l}\text { Prioritisation of 'front door' } \\
\text { interventions }\end{array}$ & $\begin{array}{l}\text { HASU staff relished the early stages of acute stroke } \\
\text { care and the potential to see rapid positive outcomes. }\end{array}$ \\
\hline \multirow[t]{2}{*}{$\begin{array}{l}\text { Factors influencing temporally } \\
\text { inconsistent care in ward } \\
\text { admissions, consultant } \\
\text { assessments in } 12 \text { and } 24 \text { hours } \\
\text { and therapy assessments in } \\
72 \text { hours }\end{array}$} & $\begin{array}{l}\text { Variations in medical, managerial } \\
\text { and allied health professional } \\
\text { staffing by time of day }\end{array}$ & $\begin{array}{l}\text { Likelihood of admission to HASU within } 4 \text { hours was } \\
\text { influenced by the number of potential patients arriving } \\
\text { at hospital. } \\
\text { Undergoing consultant assessment within } 12 \text { hours } \\
\text { and } 24 \text { hours depending on patients reaching the } \\
\text { ward during period 09:00-12:00. }\end{array}$ \\
\hline & $\begin{array}{l}\text { Variations in delivering therapist } \\
\text { assessments }\end{array}$ & $\begin{array}{l}\text { Therapists worked 'in hours' shifts - patients arriving } \\
\text { at hospital in the morning were less likely to be } \\
\text { assessed within } 24 \text { hours unless assessed on the day } \\
\text { of arrival. } \\
\text { London standards specified therapy staffing levels to } \\
\text { fully cover only } 5 \text { days per week. } \\
\text { Various attempts to cover weekend working, but no } \\
\text { current staffing model permits consistent therapy } \\
\text { provision. }\end{array}$ \\
\hline
\end{tabular}

ED, emergency department; HASU, hyperacute stroke unit.

some HASUs at night, the consultant was only called for positive confirmation if the registrar thought a patient eligible for thrombolysis (for additional data, see online supplementary file B, section 1a). This was seen as a positive educational opportunity for junior doctors, but it placed greater responsibility on senior nurses to decide whether or not to admit the patient to the HASU in cases where the stroke diagnosis was unclear.

\section{Creating continuities between different times of day}

Rapid movement of patients through the hyperacute stroke pathway required quick resolution of problems, and transfer of detailed information between team members who work at different times of day/week (see online supplementary file $\mathrm{B}$, section $1 \mathrm{~b}$ ). Key mechanisms took the form of handover meetings, multidisciplinary team meetings and ward rounds:

Bay nurse leads on his patients, going through the discharge sheet that everyone has and focuses on any particular issues that have arisen, or that the next nurse needs to be aware of. (Evening observation, $\mathrm{H} 4)$

Other ways of creating continuity included shifting or staggering staff rotas (to bridge gaps between shifts), and extending therapists' hours into the early evening.

\section{Building relationships and trust}

Delivering front door interventions consistently depended on rapid decision-making, an important facilitator of 


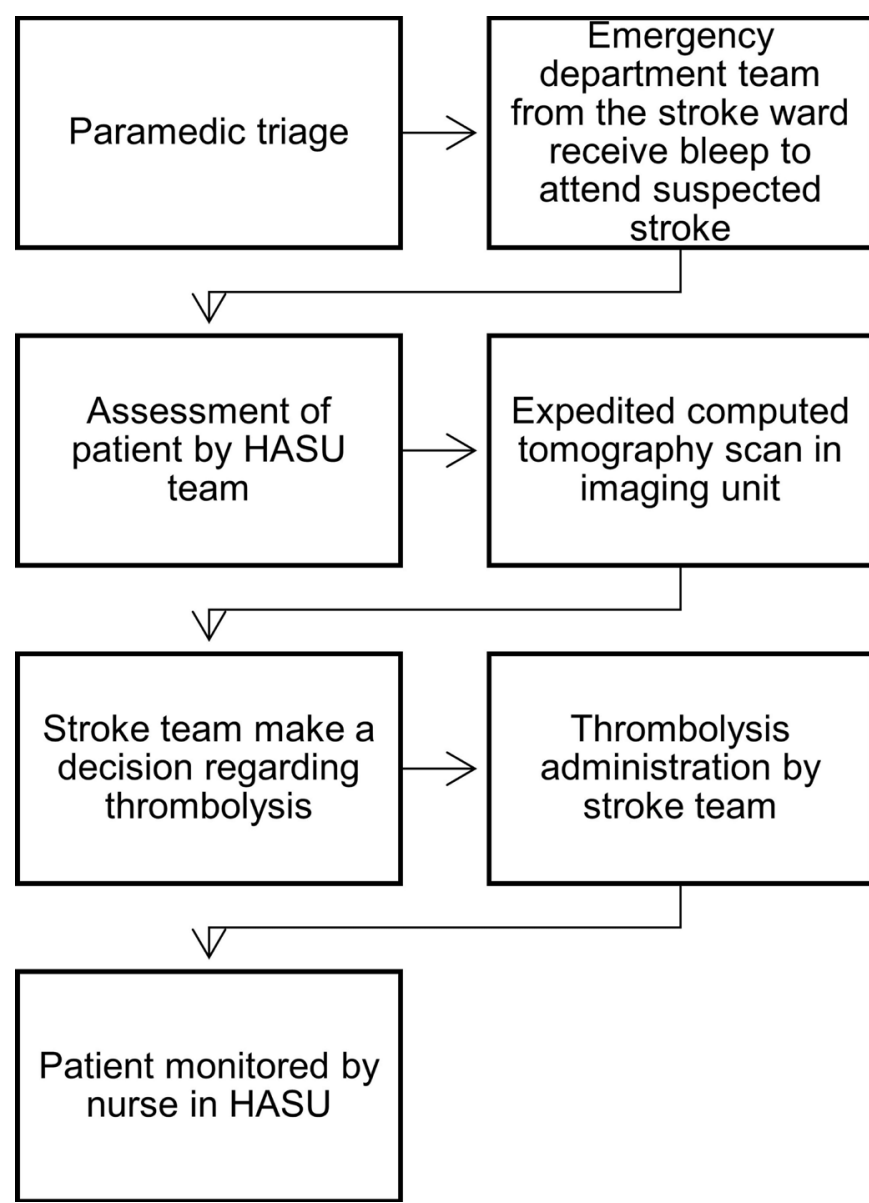

Figure 1 Thrombolysis pathway (adapted from Catangui and Slark $^{29}$ ). HASU, hyperacute stroke unit.

which was the development of strong, trusting relationships with allied disciplines, in particular ED and neuroradiology (see online supplementary file B, section 1c).

HASU staff worked alongside ED staff to assess the patient, and there were often overlaps when a patient's diagnosis was unclear, or when multiple patients presented at once. HASU staff felt that ED clinicians also valued this close relationship:

We are popular with the ED team [...] we are one of the few teams where you've got a consultant down there sweating away with them. (Consultant physician, H2)

HASU staff also had an important relationship with radiology, with prioritised access to CT scans as outlined in the London stroke service standards. The HASU team often conducted initial interpretation of CT scans, which reduced decision-making delays. HASU staff felt that this self-sufficiency strengthened their relationship with ED and radiology staff.

Prioritisation of 'front door' interventions by staff

HASU staff's enthusiasm was an important facilitator of sustained performance in delivering 'front door' interventions (see online supplementary file $B$, section $1 d$ ). Interviews and observations (eg, of the urgency with

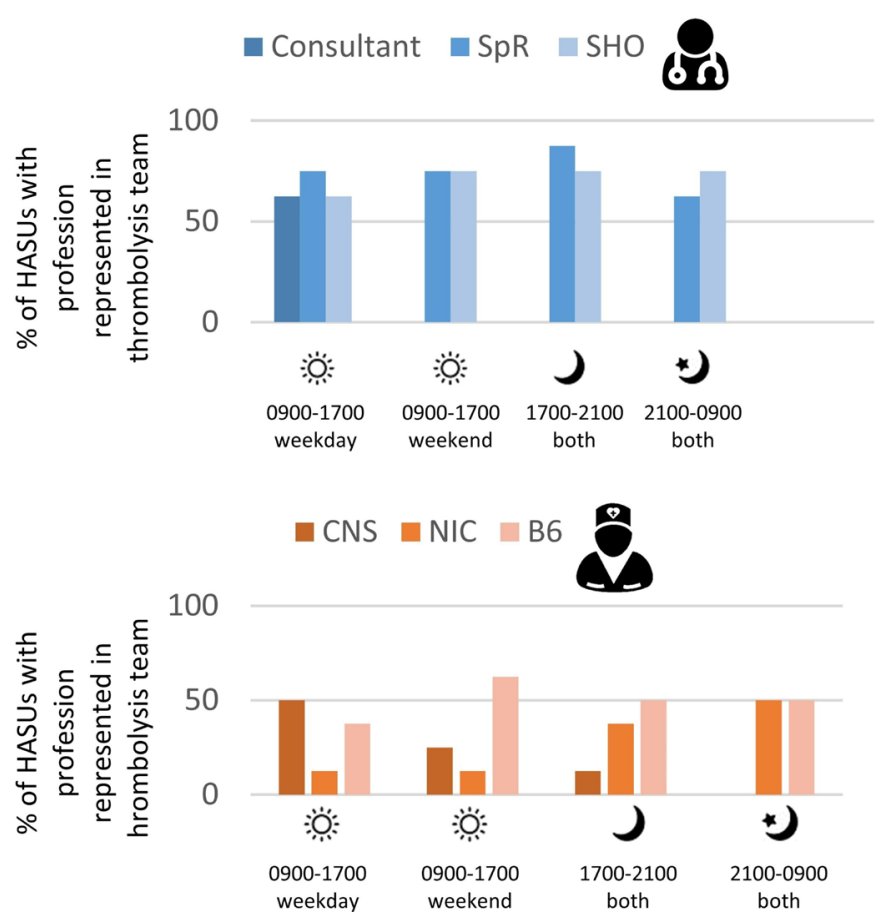

Figure 2 Staff attending suspected stroke calls in emergency department. B6, band 6; CNS, clinical nurse specialist; HASUs, hyperacute stroke units; NHS, National Health Service; NIC, nurse-in-charge; SHO, senior house officer; SpR, specialist registrar. Notes: Banding refers to NHS standardised pay grades and increases according to seniority. Staffing may have altered since the time that this information was collected.

which staff responded to calls to attend ED) suggested HASU staff relished the early stages of acute stroke care and the potential to see rapid positive outcomes:

When the stroke happens we have to work fast: run to $\mathrm{ED}$, do everything within four hours to ensure that the patient can be thrombolysed, and I've seen the patient like almost dead $[\ldots]$ we were able to save the patient's life because immediately we were able to assess, go for CT, thrombolyse the patient [...] to me it's great work. (Stroke nurse, H2)

\section{Unintended consequences of adaptations}

While extending roles out of hours was seen as an opportunity for staff development, some interviewees felt the threshold for admission to the HASU was weakened (see online supplementary file B, section 1e). Junior doctors were seen as more risk-averse than consultants, thus admitting more patients unnecessarily out of hours, in turn placing greater strain on the service at a time when it is particularly difficult to move patients from the HASU:

Some doctors, they will send them in to you, put the pressure on you to take that patient $[\ldots]$ in the morning when the consultant sees the patient, this patient has not had a stroke [...] once the patient gets in here, it's difficult to send the patient back to the wards, that becomes a big problem, they're here 
1 week, they're still waiting for medics to take the patient over. (Senior nurse, H1)

\section{Factors influencing temporally inconsistent care}

Variations in outcomes and delivery of clinical interventions in London HASUs are summarised in table 4. We explain these findings in terms of reductions in both number and seniority of medical, managerial and allied health professionals out of hours, and reductions in repatriation options out of hours.

\section{Variations in medical, managerial and allied health professionals} by time of day

Variations in delivery of interventions by time of day but not day of week (table 4) are likely to have been influenced by variations in HASU activity and staffing variations that derive from the London HASU standards (see online supplementary file B, section $2 \mathrm{a}$ ).

While some staffing levels were lower at night, the number of patients arriving also reduced, giving patients

\begin{tabular}{|c|c|}
\hline Type of variation & Examples \\
\hline $\begin{array}{l}\text { Time of day but not } \\
\text { day of the week }\end{array}$ & $\begin{array}{l}\text { Admission to hyperacute stroke units } \\
\text { within } 4 \text { hours } \\
\text { - Most likely: arriving at hospital } \\
\text { 00:00-04:00 } \\
\text { Least likely: arriving at hospital } \\
\text { 08:00-17:00 } \\
\text { Assessment by a stroke consultant } \\
\text { within } 12 \text { hours } \\
\text { - Most likely: arriving at hospital } \\
\text { 00:00-04:00 } \\
\text { Least likely: arriving at hospital } \\
\text { 16:00-20:00 } \\
\text { Assessment by a stroke consultant } \\
\text { within } 24 \text { hours } \\
\text { - Most likely: arriving at hospital } \\
\text { 16:00-20:00 } \\
\text { - Least likely: arriving at hospital } \\
\text { 04:00-08:00 }\end{array}$ \\
\hline $\begin{array}{l}\text { Day of the week but } \\
\text { not time of day }\end{array}$ & $\begin{array}{l}\text { Therapist (Physiotherapist, } \\
\text { Occupational Therapist, Speech and } \\
\text { Language Therapist) assessments } \\
\text { within } 72 \text { hours } \\
\text { - Patients admitted on Friday less } \\
\text { likely to be assessed }\end{array}$ \\
\hline $\begin{array}{l}\text { Time of day and day } \\
\text { of the week }\end{array}$ & $\begin{array}{l}\text { Therapist assessments within } \\
24 \text { hours } \\
\text { - Variation during the day Monday- } \\
\text { Friday (least likely arriving at } \\
\text { hospital 04:00-12:00) } \\
\text { Patients admitted on weekends } \\
\text { less likely to be assessed }\end{array}$ \\
\hline Outcome & $\begin{array}{l}\text { Length of stay } \\
\text { Longer for patients admitted at } \\
\text { weekends }\end{array}$ \\
\hline
\end{tabular}

a better chance of being admitted the HASU within 4 hours:

We know less people have strokes overnight [...] so we know it's like going to be quieter, but from a staffing perspective, that's why we've done the 24 hours thing, so there is always those amount of staff on.

(Senior nurse, H4)

Patients were assessed during the consultant-led ward round, which the standards required to take place daily and which commonly occurred between 09:00 and 12:00. Undergoing consultant assessment within 12 hours and 24 hours thus depended on patients reaching the ward during this period. For example, if a patient arrived at 03:00, their first consultant assessment would be likely to take place during that morning's ward round ( $\sim 6$ hour wait); if they arrived at 15:00, it would be likely to occur the following morning ( 18 hour wait):

After the ward round has finished and we've tidied up a bit, yes, you're less likely to come back and see a case, unless it was very urgent or some unusual type thing. (Consultant physician, H4)

\section{Variations in delivering therapist assessments}

Therapists generally worked 'in-hours' shifts, so patients arriving at hospital in the morning were unlikely to be assessed until the next day (see table 4), in the morning after a board round where the team make daily decisions about individual patients' care. This meant that patients arriving at hospital between 04:00 and 12:00 were the least likely to be assessed within 24 hours.

The London standards specified therapy staffing levels to fully cover only 5 days per week, and thus HASUs faced a decision on how best to use these limited resources; some chose Monday to Friday because of traditional working patterns on these days (see online supplementary file B, section $2 \mathrm{~b}$ ). The resultant gap in therapist coverage at weekends explained why patients admitted on a Friday were less likely to undergo therapy interventions within 72 hours of arrival (whereas patients admitted on the weekend were more likely to be assessed on the following Monday or Tuesday). Therapists described feeling rushed on a Friday as they struggled to get through their workload before the weekend:

Yeah I think it can be very stressful on a Friday, just if patients are going home when there've been a few discharges at the same time it can get quite complicated trying to coordinate a lot of family members, patients, staff to fill in documentation, social work, making sure a care package has gone in and completing lots of referral forms. (Speech and language therapist, H2)

Other HASUs spread their limited therapy resources into the weekend, which was reported to have a beneficial outcome on discharge figures, but participants reported a change in priorities. Assessment of new 
patients dominated, and therapeutic work or talking to families was diminished. Further, by spreading therapist resources into the weekend HASUs reduced therapist capacity during the week. Therapists in almost all HASUs suggested that existing attempts to cover weekend working resulted in reduced prioritisation of therapeutic activity, suggesting no current staffing model permits consistently sufficient therapy provision.

\section{Factors influencing length of stay}

Patients admitted at the weekend in London had a greater length of hospital stay. This related to a number of factors (see online supplementary file B, section 2c). As patients admitted at weekends were less likely to be seen by therapists, this resulted in patients not having their rehabilitation and nutritional needs potentially for 3 days in a row:

If you're nil by mouth on the Friday when you come in, say at half past four ... you could technically be nil by mouth until Monday. (Occupational therapist, H1)

Reduced therapeutic capacity could also delay discharge, thus extending length of stay:

you think, 'Well, this person can't go because they need a Physio, and we could have discharged them on the Saturday but they have to wait till Sunday or even Monday,' which [...] can cause a problem sometimes if we need beds [...] and that person's then spent another day potentially in hospital that they potentially don't need to (Occupational therapist, H8)

HASU staff suggested that social services, care homes, stroke units (acute rehabilitation units) and community rehabilitation units were significantly less likely to accept new cases at weekends. This restricted the timing of discharges from the HASU, often leading to longer stays. Input from social services and Early Supported Discharge (a service designed to accelerate the discharge home of patients in hospital ${ }^{27}$ ) was important in ensuring patients returned home or to care homes quickly once sufficiently recovered. However, social services have extremely limited weekend operation, which prevents liaison during the weekends to prepare packages of care or transfer patients (online supplementary file B, section 2c).

\section{DISCUSSION}

To our knowledge, this is the first qualitative study about the organisation of stroke care with respect to temporal variation. This study reports qualitative data that help explain the findings presented in Melnychuk et $a .^{24}$ Consistent provision of clinical interventions was underpinned by: (1) junior nursing and medical staff extending their in-hours responsibilities to cover key decision-making roles, such as that of the thrombolysis nurse; (2) intervening to bridge potential gaps caused by shift-working (staggering rotas, holding meetings to share information) and (3) HASU leadership building trust and respect across staff both within HASUs and within key specialties elsewhere in the hospital (such as ED and neuroradiology). Key issues leading to temporal variation in care provision included reductions in medical, managerial and allied health professions, and significantly reduced options for repatriation to other acute services and community services, at night and on the weekend. Variations resulted in greater pressure on the ward from low thresholds for admission at night, dilution of staff capacity and bottlenecks in repatriation pathways. Some of these effects were mitigated by strategies to create ward space and expedite discharges on a Friday, but these strategies had a number of unintended negative consequences in terms of patient outcomes.

The London service standards were an important influence on delivery of clinical interventions, whether consistent or inconsistent. Where standards required 24/7 availability of staff, for example, nurses, aspects of care associated with these staff groups tended to be delivered consistently, regardless of time of day or day of week. Where standards required that a key activity was conducted on a daily basis (such as the consultant-led ward round), the likelihood of patients undergoing the associated intervention varied significantly according to when they were admitted. Finally, where standards specified staffing levels to cover only 5 days (as with therapies), it was not possible to provide interventions consistently over 7 days, regardless of local adaptations employed.

The strengths of our study are founded on detailed data collection in each London HASU at different times of day both during the week and at weekends, providing a rich picture of the realities of organising and providing a high-performing acute care system. Observing and comparing how eight sites organised themselves in different ways to meet the same standards affords generalisability to our results. There were several limitations to the study. First, we did not study any hyperacute stroke services operating within a different service model (whether centralised or non-centralised). The lack of a comparator limited our confidence that our findings explain 24/7 care per se (as compared with a centralised model of care) with respect to the quantitative analyses in Melnychuk et al..$^{24}$ Second, we did not interview all relevant professions within the studied organisations, for example, pharmacy, emergency medical practitioners and so on. Therefore, our perspective on important working relationships beyond the HASU was based on HASU staff perceptions, though they were supported by our own observations particularly of ED coordination. Finally, these services develop constantly, and some aspects of provision such as staffing levels are likely to have changed.

\section{Recommendations for research, policy and practice}

This study adds to current knowledge as the first qualitative study to provide explanations for how and why temporal variation arises in stroke, and how it can be mediated. Our study was strongly in accord with the 
growing body of literature suggesting that different patterns of temporal variation are relevant to specific clinical interventions and outcomes. ${ }^{7819}$ Clinical decision-makers looking to improve temporal consistency in stroke care should consider different weekend therapy working patterns and extended working hours for all clinical disciplines. However, managers should be cautioned that without increased resource, bottlenecks in workload are caused by reduced staffing and repatriation options at weekends, placing staff under strain and deprioritising non-urgent patients. Our findings are relevant internationally with respect to reducing temporal variability in stroke outcomes, ${ }^{56}$ and in other acute care settings. ${ }^{4} 8$

Policy makers and clinical decision-makers promoting 7-day health services should apply clear service standards, which facilitate the delivery of clinical interventions. The standards should consider how each health profession might contribute to 7-day care, at what time of day, and what capacity is required to deliver this. Standards must recognise how these will influence patient flow, and acknowledge service interdependencies both within and beyond the hospital perimeter. Multidisciplinary evaluations of efforts to provide 7-day care such as this can help planners avoid unintended consequences of service reorganisations, both in terms of gaps in the models implemented and how clinical teams respond to these.

Researchers need to examine other efforts to deliver clinical interventions $24 / 7$ in stroke and other clinical settings. In-depth analysis of the interdependencies that influence $24 / 7$ delivery of care, both within and beyond the host hospital, would be of value.

\section{Author affiliations}

${ }^{1}$ Department of Applied Health Research, University College London, London, UK ${ }^{2}$ City University of New York System, New York City, New York, USA

${ }^{3}$ Barts Health NHS Trust, London, UK

${ }^{4}$ Department of Applied Health Research, Imperial College London, London, UK

${ }^{5}$ Department of Psychology, University of Exeter, Exeter, UK

${ }^{6}$ Department of Neurology, University College London, London, UK

${ }^{7}$ Clinical Effectiveness and Evaluation Unit, Royal College of Physicians, London, UK

${ }^{8}$ Comprehensive Stroke Service, University College London Hospitals NHS

Foundation Trust, London, UK

Correction notice This article has been corrected since it was published. Authorship has been updated.

Contributors NJF, SM, AGR, AIGR, MMB and RS contributed to the conception and design of the work. GBB, AB-L, JE and PX acquired the interview and observation data. GBB, AB-L, JE, AIGR, MM and NJF analysed the data. All authors interpreted the data, drafted the work and revised it critically and gave final approval of the version to be published. All authors agree to be accountable for all aspects of the work in ensuring that questions related to the accuracy or integrity of any part of the work are appropriately investigated and resolved.

Funding This paper presents independent research commissioned by the National Institute for Health Research (NIHR) Health Services and Delivery Research Programme, funded by the Department of Health and Social Care (study reference 10/1009/09). RS was in part supported by the NIHR University College London Hospitals Biomedical Research Centre. NJF is a senior investigator of NIHR, and NJF and SM were in part supported by the NIHR Collaboration for Leadership in Applied Health Research and Care North Thames at Bart's Health NHS Trust.

Disclaimer The views expressed are those of the authors and not necessarily those of the NHS, the NIHR or the Department of Health and Social Care.
Competing interests RS is lead consultant of the HASU in University College London Hospitals NHS Foundation Trust. AGR is the National Clinical Director for Stroke in England and London Stroke Clinical Director.

Patient consent for publication Not required.

Ethics approval This study was approved by the National Research Ethics Service Committee London-Westminster (Reference No 14/L0/1355).

Provenance and peer review Not commissioned; externally peer reviewed.

Data sharing statement Interviews and observational data from this study are personally identifiable for patients and staff, and are therefore not available for data sharing.

Open access This is an open access article distributed in accordance with the Creative Commons Attribution 4.0 Unported (CC BY 4.0) license, which permits others to copy, redistribute, remix, transform and build upon this work for any purpose, provided the original work is properly cited, a link to the licence is given, and indication of whether changes were made. See: https://creativecommons.org/ licenses/by/4.0/.

\section{ORCID iDs}

Georgia B Black http://orcid.org/0000-0003-2676-5071

Penny Xanthopoulou http://orcid.org/0000-0002-1510-3382

Naomi J Fulop http://orcid.org/0000-0001-5306-6140

\section{REFERENCES}

1. NHS England. Five year forward view London: NHS England. 2014 www.england.nhs.uk/wp-content/uploads/2014/10/5yfv-web.pdf.

2. Bell A, McDonald F, Hobson T. The ethical imperative to move to a seven-day care model. J Bioeth Inq 2016;13:251-60.

3. NHS England. Next steps on the NHS five year forward view UK: HM Government. 2017 https://www.england.nhs.uk/wp-content/uploads/ 2017/03/NEXT-STEPS-ON-THE-NHS-FIVE-YEAR-FORWARD-VIEW. pdf (Accessed 14th Sep 2017).

4. Sharp AL, Choi H, Hayward RA. Don't get sick on the weekend: an evaluation of the weekend effect on mortality for patients visiting US EDs. Am J Emerg Med 2013;31:835-7.

5. Saposnik G, Baibergenova A, Bayer N, et al. Weekends: a dangerous time for having a stroke? Stroke 2007;38:1211-5.

6. Albright KC, Raman R, Ernstrom K, et al. Can comprehensive stroke centers erase the 'weekend effect'? Cerebrovasc Dis 2009;27:107-13.

7. Bray BD, Cloud GC, James MA, et al. Weekly variation in healthcare quality by day and time of admission: a nationwide, registrybased, prospective cohort study of acute stroke care. Lancet 2016;388:170-7.

8. Aldridge $\mathrm{C}$, Bion J, Boyal A, et al. Weekend specialist intensity and admission mortality in acute hospital trusts in England: a crosssectional study. Lancet 2016;388:178-86.

9. Black N. Is hospital mortality higher at weekends? If so, why? Lancet 2016;388:108-11.

10. Freemantle N, Ray D, McNulty D, et al. Increased mortality associated with weekend hospital admission: a case for expanded seven day services? BMJ 2015;351:h4596.

11. McKee M. The weekend effect: now you see it, now you don't. BMJ 2016;353:i2750.

12. Palmer WL, Bottle A, Davie C, et al. Dying for the weekend: a retrospective cohort study on the association between day of hospital presentation and the quality and safety of stroke care. Arch Neurol 2012:69:1296-302.

13. Roberts SE, Thorne K, Akbari A, et al. Mortality following stroke, the weekend effect and related factors: record linkage study. PLoS One 2015;10:e0131836.

14. Bray BD, Steventon A. What have we learnt after 15 years of research into the 'weekend effect'? BMJ Qual Saf 2017;26.

15. Walker AS, Mason A, Quan TP, et al. Mortality risks associated with emergency admissions during weekends and public holidays: an analysis of electronic health records. Lancet 2017;390:62-72.

16. Mathew A, Fyyaz SA, Carter PR, et al. The enigma of the weekend effect. J Thorac Dis 2018;10:102-5.

17. Conway R, Cournane S, Byrne D, et al. Improved mortality outcomes over time for weekend emergency medical admissions. Ir J Med Sci 2018;187:5-11.

18. Khoshchehreh M, Groves EM, Tehrani D, et al. Changes in mortality on weekend versus weekday admissions for Acute Coronary Syndrome in the United States over the past decade. Int J Cardiol 2016;210:164-72. 
19. Balinskaite V, Bottle A, Shaw LJ, et al. Reorganisation of stroke care and impact on mortality in patients admitted during weekends: a national descriptive study based on administrative data. BMJ Qual Saf 2018;27.

20. Ramsay Al, Morris S, Hoffman A, et al. Effects of centralizing acute stroke services on stroke care provision in two large metropolitan areas in England. Stroke 2015;46:2244-51.

21. Morris S, Hunter RM, Ramsay Al, et al. Impact of centralising acute stroke services in English metropolitan areas on mortality and length of hospital stay: difference-in-differences analysis. BMJ 2014;349:g4757.

22. Fulop NJ, Ramsay Al, Perry C, et al. Explaining outcomes in major system change: a qualitative study of implementing centralised acute stroke services in two large metropolitan regions in England. Implement Sci 2016;11:1.

23. Allen M, Pearn K, James M, et al. Maximising access to thrombectomy services for stroke in England: a modelling study. Eur Stroke J 2019;4.
24. Melnychuk M, Morris S, Black GB, et al. Variation in quality of acute stroke care by day and time of admission: prospective cohort study of weekday and weekend centralised hyperacute stroke unit care and non-centralised services. BMJ Open.

25. Tong A, Sainsbury P, Craig J. Consolidated criteria for Reporting Qualitative Research (COREQ): a 32-item checklist for interviews and focus groups. Int J Qual Health Care 2007;19:349-57.

26. Miles M, Huberman A. Qualitative Data Analysis. London: Sage, 1994.

27. Early Supported Discharge Trialists. Services for reducing duration of hospital care for acute stroke patients. The Cochrane Database of Systematic Reviews 2005;2.

28. Carr BG, Jenkins P, Branas CC, et al. Does the trauma system protect against the weekend effect? J Trauma 2010;69:1042-8.

29. Catangui EJ, Slark J. A thrombolysis pathway for patients following acute ischaemic stroke. Nurs Stand 2012;26:35-42. 